\title{
The Effect of Face-Conclude-Answer Strategy in the Achievement of Fourth Grade Students in Chemistry
}

\author{
Fadhil Kadhum Abbas ${ }^{1}$, Ibtisam Jaafer Jawad ${ }^{2}$, Amjed Mirza Oda ${ }^{3}$ \\ ${ }^{1}$ Post Graduate, ${ }^{2}$ Assist Prof., ${ }^{3}$ Assist Prof., Science Department, College of Basic Education, \\ University of Babylon, Iraq
}

\begin{abstract}
The aim of the research is to find out the effect of the (face-conclude-answer) strategy on the achievement of fourth-grade students in chemistry and branched thinking. Research sample was 53 students divided into two groups: A group was 27 students as experimental group and B group was 26 students as control then equalized in the following variables: academic achievement of the chemistry subject for the third intermediate grade, previous scientific knowledge of their information, intelligence test, chronological age and branched thinking test. The test was 35 items, where 26 was multiple choices question and 9 are article paragraphs. The validity was verified after the experiment in the academic year 2019-2020 by the researcher on the two research groups and according to the teaching plans that were prepared for them and applied the achievement test and the results showed the superiority of the experimental group that was studied according to the strategy (faced -conclude- answer) on the group that studied according to the usual method in a variable Academic achievement.
\end{abstract}

Keywords: Strategy (face - conclude - answer), achievement, science fourth graders, chemistry, branched thinking.

\section{Introduction}

Human instinct is the essence of life and the basis for practice in it, and it is the true entrance to the human being who is the basic nucleus of society. He always needs to keep pace with the renewal of life and achieve the integration of development for his personality. This integration can only be achieved by education, so education is an active organizational process for the system of participation and interaction, and the compatibility of individual activity ${ }^{(1)}$. The specialists in scientific education confirm that teaching in general and teaching chemistry in particular is not just a transfer of knowledge to students. Rather than it is a process that helps in building their knowledge and develop their understanding and thinking about the natural world and are interested and their integration and development of all aspects of their personalities ${ }^{(2)}$. Education can achieve its desired goals in order to highlight the energies of the learner and reveal his capabilities and reach him to the maximum possible learning, thinking and application. Studying chemistry helps the student to understand and think in the era of science and technology that has become difficult for a student to live in the twenty-first century without an understanding of the nature of science. Also, it gives familiarity with basic chemical information, the use of branched thinking to solve life problems, and make sound decisions in light of scientific and technological developments ${ }^{(3)}$. So the best way to improve chemistry teaching can only be done through the use of a scientific method based on research and experimentation. The use of reason and thinking in problem solving is a missing factor in traditional education. Some of the criticisms and shortcomings faced the educational philosophy in the past twenty years,especially the teaching method that led to a kind of change and development, whether in form or content ${ }^{(4)}$. The way to improve the level of students in the learning process is to develop their abilities to choose appropriate strategies for learning is how to activate their previous knowledge and employ them in current learning situations ${ }^{(5)}$. As for the subject of chemistry, problem-solving strategies can be adopted to help students understand the proposed solution to the problem. This seeks other solutions, in addition to controlling and students will improve their understanding and comprehension, planning, management and problem-solving ${ }^{(6)}$. Teaching strategy is extremely 
important in three basic aspects (the teacher, the learner, and the educational subject). For the teacher, to reach his goals clearly and in a logical sequence and the learner has ability to follow the educational subject in a comfortable gradient as it provides. These strategies and models that will work is the strategy (faced - concluded - solve) as it is seen as one of the problem-solving strategies. This strategy activates are the previous information that students know and activates their ability to find solutions to the problem at hand, as well as combining the correct and wrong ideas and reaching the right ideas themselves. Especially in chemistry, as it is no longer hidden from anyone, that the extremely important role is chemistry plays as one of the main areas of technical development in other theoretical sciences, such as physics, mathematics, geology, and applied sciences such as medicine, engineering, and agriculture. It can be said that the areas of its spread are very wide (8). This achievement influences this comprehensive development outcome for students, so its effectiveness is positive and its educational importance in the student's behavior towards the best and helps them to interact with their environment ${ }^{(10)}$. The branched thinking: thinking makes the learner move in his thinking to unspecified horizons and unconventional pathways. This helps him come up with new ideas, especially when he is asked for evidence or reasons about a phenomenon. It also includes a solution to a problem in a unique and expert way producing new solutions to the problem and thus reflected on the scientific level and school performance ${ }^{(11)}$. Also branched thinking skills are among the most important goals that educational institutions seek to achieve $\mathrm{e}^{(12)}$.

A strategy (face - conclude - answer) is an teaching strategy of problem-solving strategies followed by the teacher (the researcher) with students as the researcher divides the subject of the lesson into axes and then identifies a problem for each of them and takes into account that the problem is solvable in more than one way, then the teacher presents the problem for learners in the form of a question that students try to reach a solution. Their knowledge and previous experience then choose the teacher with the help of the educated answer will reach the most accurate and correct solution to the problem ${ }^{(13)}$.

Because there are no studies that dealt with a strategy faced - concluded - answer, so the researcher turned to studies that dealt with the problem-solving method considering that this strategy is derived from the problem-solving method. From these studies is the effect of using a problem-solving method on the achievement of middle school students in geography ${ }^{(14)}$.

Experimental: The researchers follow the experimental method to achieve the two goal s of the research and the experimental design was the partial accurate in one description for the equal groups as shown in table 1.

Table 1: The experimental method for the strategy under study.

\begin{tabular}{|l|l|c|c|}
\hline Group & Independent variable & Dependent variable & Research tool \\
\hline Experimental & Face - conclude - answer strategy & $\begin{array}{c}\text { The achievement of branched } \\
\text { thinking }\end{array}$ & $\begin{array}{c}\text { Post test achievement } \\
\text { Branched thinking test }\end{array}$ \\
\hline Control & Regular method & \begin{tabular}{c} 
thes \\
\hline
\end{tabular}
\end{tabular}

The community under study the students of science fourth grade in the governmental day school that belong to the general directorate of education in Holly Karbala at 2019-2020. The researcher chose Almakasib preparatory school randomly which included three groups of science fourth grade (A, B, and C). Group A was chosen randomly to be experimental group which consist of 27 students. This group would be taught by face-conclude-answer strategy. In the same procedure, the researchers chosen group B to be control, which is consist of 26 students.

Equivalent of The Groups Research: the two groups were equalized according to academic achievement of the chemistry subject for the third intermediate grade, previous scientific knowledge of their information, intelligence test, chronological age and branched thinking test as in table 2 . 
Table 2: Equalized group $A$ and B

\begin{tabular}{|c|c|c|c|c|c|c|c|c|}
\hline \multirow{2}{*}{ Equivalents } & \multicolumn{2}{|c|}{ Average } & \multicolumn{2}{|c|}{ Variance } & \multirow{2}{*}{$\begin{array}{l}\text { Degree of } \\
\text { freedom }\end{array}$} & \multicolumn{2}{|c|}{ T value } & \multirow{2}{*}{$\begin{array}{c}\text { Statistic } \\
\text { significance at } \\
0.05\end{array}$} \\
\hline & $\begin{array}{l}\text { Experimental } \\
\text { (27) }\end{array}$ & $\begin{array}{l}\text { Control } \\
\text { (26) }\end{array}$ & $\begin{array}{l}\text { Experimental } \\
\text { (27) }\end{array}$ & $\begin{array}{l}\text { Control } \\
\text { (26) }\end{array}$ & & Calculated & Table & \\
\hline Chronological age & 194.07 & 194.12 & 49.84 & 41.47 & 51 & 0.022 & 2.000 & Non sign. \\
\hline $\begin{array}{l}\text { Previous scientific } \\
\text { knowledge }\end{array}$ & 62.59 & 62.77 & 75.48 & 89.54 & 51 & 0,071 & 2.000 & Non sign. \\
\hline $\begin{array}{l}\text { Marks of chemistry in } \\
3^{\text {rd }} \text { class }\end{array}$ & 11.37 & 11.12 & 3.93 & 3.31 & 51 & 0,487 & 2.000 & Non sign. \\
\hline Intelligence test & 21.22 & 20.81 & 69.64 & 69.68 & 51 & 0,181 & 2.000 & Non sign. \\
\hline Branched thinking test & 43.44 & 44.38 & 120.33 & 118.17 & 51 & 0,313 & 2.000 & Non sign. \\
\hline
\end{tabular}

Control of foreign variables: Exotic variables: are types of independent variables that must be controlled or prevented from affecting the study by following a specific method of controlling the variables. The control of exotic variables is one of the important procedures in experimental research in order to provide the internal honesty of the experimental design and for the researcher to attribute most of the variation in the dependent variable to the independent variable and not to other variables. Accordingly, the researchers tried to control the foreign variables that he saw that might affect the integrity of the research as follows:

Accidents accompanying the experiment: During the period of application of the experiment demonstrations were witnessed (October 25 Revolution), which led to a break in full-time work in most of the provinces of Iraq, and after that, the working hours returned to normal on 27/11/2019.

Experimental extinction: There were no breakdowns, transfers, or absences except for some individual cases throughout the experiment.

Sample selection: The two research groups were randomly chosen and the two groups were equal in number of variables. This enables the researcher to avoid the effect of individual differences between the two research group, which may affect the results of the research.

Growth factor: Given that the trial period is uniform for the two research groups and the students 'ages are close to the two groups, so what happens will be equal to the growth of the two groups, so this factor did not affect the research.

Measurement tools: The researcher used the same measuring tools for the two research groups: (achievement test, branched thinking test). The effect of experimental procedures: The researcher worked to limit the impact of the experimental procedures that could affect the dependent variable during the course of the experiment, and here is a presentation of these procedures whose impact has been determined.

Research confidentiality: The researcher was keen on confidentiality of the research, in agreement with the school administration and the teacher of the article not to inform the students of the nature of the research and the application of the experiment, as they were told that the researcher is a new teacher in the school so that their activities do not change or deal with the researcher.

Duration of the experiment: The duration of the experiment was equal for the two research groups (10 weeks), as it started on (Tuesday) corresponding to (10/8/2019) and ended on (Tuesday) corresponding to (16/2/2020).

Academic Subject: The two research groups were studied in the same subject, which are the three chapters (1-3 chapters) of the book of chemistry $(2019,10$ th edition), to be taught for the fourth scientific grade by the Iraqi Ministry of Education for the academic year (2019-2020).

Teacher: The researcher studied the two research groups himself throughout the experiment, which gives the results of the experiment accuracy and objectivity, because the difference of teachers may affect the results of the experiment and hide the effect of the independent variable.

Place: The experiment was applied in the same school, and it is a prep course. 
Distribution of lessons: It was agreed with the headmaster and the teacher of the subject on equal distribution of lessons between the two research groups at three classes per week for each group, provided that one lesson for each group is on the same day,

\section{Search requirements:}

The search application requests the configuration of the following supplies:

Course Identification: The course material is determined by the three (first, second, and fifth) chapters of the Chemistry Book (2019, 10th edition) scheduled for teaching for the fourth academic year of the year by the Iraqi Ministry of Education (2019-2020).

Formulating behavioral goals: After defining the academic subject, the researcher formulated (191) behavioral goals according to Bloom >s classification distributed on (Remembering, understanding, applying, analyzing, synthesizing, evaluating), and these goals were presented to a group of experts and specialists in the field of education, psychology, teaching method, chemistry teachers and supervisors, to express their opinions and observations, and the percentage and value of Kay square for each of the goals was calculated Behavior and compare it with the tabular value of (51) with a degree of freedom (2) and at the level of significance (0.05) and the results showed the validity of all behavioral goals, a set of teaching plans were prepared for the two research groups according to the content of the book of chemistry $(2019,10$ th edition) to be taught to students of the fourth scientific grade for the academic year (2019-2020m) goals and tuberculosis Cauterizing, where it was set up (40) teaching plan by (20) plan teaching experimental group according (strategy faced - concluded - duty) and (20) teaching plan for the control group according to the regular method.

\section{Search tool}

The steps of the research tools (achievement test) were prepared as follows:

Determining the purpose of the achievement test: One of the requirements for applying the current research is preparing an achievement test that is used to measure the academic achievement of the research sample in chemistry for the three semesters to be taught in the first semester, so the researcher has prepared an achievement test related to the course that was taught and behavioral purposes related to it It matches the level of the research sample.

Determine the goal of the test: The aim of the test is to measure the achievement of fourth-grade students (the research sample) in chapters (first, second, and fifth) of the textbook of chemistry after teaching it. Determining the number of test items: The researcher determined the number of items that make up the achievement test, as the number of test items reached (35) test items, including (26) objective paragraphs and (9) article paragraphs.

Preparing the specifications table: The specifications table was prepared according to its basic steps where he determined the relative importance of the three chapters: (basic concepts in chemistry, gases, nuclear chemistry), and he also determined the relative weights for each level of the cognitive field in the light of the number of pages of the book chapters, and after Defining test items with (35) items. The number of questions for each cell in the specifications table was calculated.

\section{Drafting test instructions:}

A. Answer Instructions: After verifying the validity of the test items, instructions for the test are given, giving an illustrative example of how to answer.

\section{B. Correction Instructions:}

1. Objective Paragraph: For the purpose of correcting students 'answers, the researcher prepared a key for correction, and gave (one score) for the correct answer and a score (zero) for the wrong or abandoned answer or in the case of choosing more than one answer, and thus the total score for the objective test becomes (26) degrees.

2. The essay paragraph: The researcher prepared a test for correction and was presented to some experts and arbitrators, where he gave (two grades) for the complete correct answer, (one degree) for the incomplete answer and the degree (zero) for the abandoned or incorrect answer, thus the total score for the fried test becomes (18) Degree.

Sincerity of the test: The test truthfully means that the test measures what was set to measure it, that is, the honest test measures the function for which it was designed and does not measure anything else. To verify the validity of the test, the researcher adopted two types of honesty:

\section{The first exploratory application: The}


achievement test was applied in its first exploratory stage to a group of fourth-grade students without scientific research, and the number of students was (40) students, the purpose of which is to know the clarity of the test instructions and instructions and the extent of understanding and clarity of the test items for students and calculating the necessary time period For the test, as the researcher recorded the exit time for each student, and by calculating the mathematical mean of time, he found that the time needed to answer all the test items is (40) minutes.

The second exploratory application: The test was applied to a sample consisting of (100) students in the fourth grade of science without the research sample, and its purpose is to analyze the statistical test achievement paragraphs represented by the difficulty of the paragraph, distinguishing the paragraph, and the effectiveness of wrong alternatives.

Statistical analysis of achievement test items: The achievement test items were analyzed as follows:

Paragraph difficulty: By performing the statistical analysis of the achievement test items, it was found that the difficulty factor of its paragraphs ranges from (0.46$0.65)$. Thus, the achievement test paragraphs are all good and their difficulty is appropriate.

- Paragraph discrimination: One of the important characteristics that should be provided in the test items is the distinguishing feature, which means the possibility of items or paragraphs to examine the individual differences of students. The test items are valid as the items discrimination factor is $(20,0)$ and above, and the value of the discrimination factor of achievement test items Between (0.31 - 0.74), and thus the achievement test items are considered to be a good and suitable discrimination factor.

- Effectiveness of wrong alternatives: The researcher performed a statistical analysis of the test items and it became clear from that the alternatives to the achievement test items are all effective and thus all of them are considered appropriate.

Stability of the test: The stability test of the test depends on the relationship between each of the other or all of the test items, and this is evident through the stability of its scores and the consistency of its paragraphs. Paragraphs of the test have a clear meaning that must be honest and steady at the same time.

Method of finding test reliability: Midway segmentation method: This method is one of the most used method, due to the fact that it avoids the disadvantages of some other method. Pearson correlation between the degrees of the odd and even paragraphs of paragraphs, the coefficient of stability and its value (0.88) was obtained, and since the coefficient of the halffragmentation stability of the test did not measure the overall homogeneity of the test (because it is only half stability), therefore the correction was made using the Spearman-Brown factor, as it reached (0.94) It is a good stability coefficient from the expert's point of view.

The application of the research tool: The experimental and control research groups were notified of the date of applying the achievement test a week before it was conducted and it was applied after the completion of teaching the specific subject for the two research groups at one time, and the researcher supervised the process of applying the test.

Statistical means: The researcher used the t-test equation for two independent samples to conduct equivalence between the experimental and control groups, and the Pearson correlation equation, as the researcher used the equation to correct the correlation coefficient between the two test parts (degrees of individual and even paragraphs) after being extracted by the Pearson correlation coefficient and the bag Statistical spss, and Excel.

\section{Results and Discussion}

The experimental group students who studied according to the strategy (face - deduce the duty) surpassed the students of the control group who studied according to the usual method in the achievement test, and this is consistent with studies that confirmed the superiority of the experimental group that was studied according to the strategy (face - conclude - Answer) the control group that was studied according to the usual method as shown in table 3 . 
Table 3: The statically result of sample under study

\begin{tabular}{|c|c|c|c|c|c|c|c|c|c|}
\hline \multirow{2}{*}{ Item } & \multirow{2}{*}{ Group } & \multirow{2}{*}{$\begin{array}{l}\text { No. of } \\
\text { students }\end{array}$} & \multirow{2}{*}{ Average } & \multirow{2}{*}{ S.D } & \multirow{2}{*}{ Variance } & \multirow{2}{*}{$\begin{array}{l}\text { Degree of } \\
\text { freedom }\end{array}$} & \multicolumn{2}{|c|}{ T value } & \multirow{2}{*}{$\begin{array}{l}\text { Significance } \\
\text { value at } 0.05\end{array}$} \\
\hline & & & & & & & Calculated & Table & \\
\hline 1 & Experimental & 27 & 39.04 & 3.13 & 9.81 & \multirow{2}{*}{51} & \multirow{2}{*}{5.042} & \multirow{2}{*}{2} & \multirow{2}{*}{ Significance } \\
\hline 2 & Control & 26 & 33.42 & 4.48 & 23.29 & & & & \\
\hline
\end{tabular}

\section{Conclusions}

The strategy of face-conclude-answer is a good tool for rise of students' level in thinking to be very creative and compatible with chemistry lessons. According the statistical study, we found there is significance relationship between the experimental and control groups. The average of students' marks in chemistry was developed after using face-conclude-answer strategy, which will be a good recommendation for chemistry teaching.

Ethical Clearance: The Research Ethical Committee at scientific research by ethical approval of both MOH and MOHSER in Iraq

\section{Conflict of Interest: None}

Funding: Self-funding

\section{References}

1. Maroun Y, Teaching method between theory and practice in the light of modern educational trends and teaching the Arabic language in basic education, Modern Book Foundation, Tripoli, Lebanon,2008; 10-25

2. Abdel Salam M,Teaching science and the requirements of the times, 1st floor, Arab Thought House, Cairo, Egypt, 2006; 148-158

3. Al-Yasiri N, Muhammad B, their foundations, theories, components and teaching plans, 1st edition, Methodological House for Publishing and Distribution, Jordan,2016; 18-29

4. Abdul Bari M Sh, Reading comprehension strategies (based on theoretical principles and their practical applications), 1st edition, Al Masirah Publishing House, Amman, Jordan,2010;43-60.

5. Abu Jahjouh, Y M, The nature of physics and its relationship to teaching method of physics teachers in secondary schools in Palestine, Al-Aqsa
University Journal (Humanities Series), 2013; 6(2):56-71.

6. Al-Deeb, H, Farouk J, Self-evaluation and its impact on students 'motivation towards learning and their level of academic achievement, 1st edition, Horus International Foundation for Publishing and Distribution, Alexandria,2013;23-30.

7. Al-Mashhadani, A N, Educational method and models in teaching mathematics, the Arabic edition, Al Yarouzi Scientific House for Publishing and Distribution, Amman, 2011; 33-45.

8. Ambo Saeedi, A Kh, Suleiman A, Method of Teaching Science, Educational Concepts and Applications, 1st Floor, Dar Al Masirah, Amman, Jordan,2009;29-40.

9. Beeth, M. E, Teaching the conceptual change: using status as Met a cognitive Tool, Science Education,1998, 82 (3): 455-466.

10. Davis, Charles H, 2nd Edition, In Encyclopedia of library and information science, Marcel Dekker, New York, 2003.

11. Hameed, S M, The effect of overlapping wave strategies in developing branched thinking among literary fifth graders in the subject of history, (published research), College of Education for Humanities, University of Diyala,2015;55-76.

12. Zayer SA, Ohoud S H, Alaa A M, Suggested educationalapplications according to the dimensions of sustainable development, 1st edition, Al-Amir Office for Printing and Publishing, Baghdad, Iraq, 2015;34-48.

13. Zayer, S A, Contemporary Educational Encyclopedia, 1st edition, Safaa House for Publishing and Distribution, Amman, 2017;62-75.

14. Ismail, B H, Strategies for teaching Arabic language, theoretical frameworks and practical applications, 1st edition, Dar Al-Manhahej for Publishing and Distribution, Amman, 2013;31-49. 